\title{
Reminiscências: Conselheiro Crispiniano Soares, o primeiro lente de Direito Romano da nossa Academia
}

\author{
Manoel Martins de Figueiredo Ferraz \\ Professor-adjunto de Direito Romano da Faculdade de Direito da USP
}

\begin{abstract}
RESUMO: Os cursos jurídicos, criados em 1827, em duas cidades - São Paulo e Olinda - tiveram papel preponderante na formação cultural e política do Brasil, tanto na sua fase monárquica quanto na republicana. A criação da cadeira de Direito Romano, que se deu em 1854, propiciou o estudo do "Corpus Iuris Civilis" e possibilitou a difusão dos princípios da Escola Histórica, alicerçados nas doutrinas de Puchta e Savigny. O primeiro Professor de Direito Romano, na Academia de São Paulo, foi o conselheiro Crispiniano Soares, adepto da Escola Histórica e que teve especial atuaçāo nāo só como lente, mas como político e administrador. Professor por concurso, foi, durante 35 anos, exemplo de abnegação aos estudos romanísticos.
\end{abstract}

RÉSUMÉ: Les cours de Droit, crées en 1827, dans deux villes - Saint Paul et Olinda - ont eu un rôle prépondérante dans la formation cultural et politique du Brésil, soit das sa fase monarchique soit dans la fase republicaine. La création de la chaire de Droit Romain en 1854, a favorisé l'étude du "Corpus Iuris Civilis", outre Ja difussion des principes de l'École Historique fondés dans les doctrines de Puchta et de Savigny. Admis a l'Académie par concours, et partisan de l'École Historique, le conseiller Crispiniano Soares a ete le premier Professeur de Droit Romain de l'Académie de Droit Saint Paul, où, pendant 35 ans, il a donné l'éxemple d'abnégation aux études romanistiques. Il a s'occupé non seulement de l'enseignement, mais aussi de la politique et de l'administration.

Ao ensejo das homenagens que esta Casa prestou ao Professor Emérito Alexandre Correia, saudoso catedrático da cadeira de Direito Romano - e as quais juntamos as nossas - fizemos referência de passagem a outra figura ímpar nos anais da Academia, justamente a do primeiro lente de Direito Romano: o Conselheiro Crispiniano Soares.

Na década de 40, a Associação dos Antigos Alunos (AAA) promoveu concurso sobre a vida e a obra de Crispiniano, uma das figuras mais singulares da Academia e como aluno participamos do referido concurso, o que nos permitiu traçar, com as deficiências de acadêmico, o perfil daquele que veio a ser o primeiro lente da cadeira de Direito Romano.

No ano de 1853, pelo Decreto no 1.134 , é que os cursos jurídicos de Sāo Paulo e Olinda passaram a ser denominados faculdades de Direito; é o que nos informa o mestre desta Casa, Professor José Carlos Moreira Alves, em artigo publicado na revista Índex, de junho de 1976, intitulado "Panorama da literatu- 
ra romanística do Brasil" e que precisa o ano de 1854 como o da criação da cadeira de Direito Romano nas duas faculdades.

João. Crispiniano Soares nasceu em Guarulhos, então Freguesia da Conceição dos Guarulhos, em 1809, um pequeno agrupamento de casas, distando 16 quilômetros da pacata cidade de São Paulo. Era filho natural do major José Soares de Camargo e de Dona Inês Joaquina de Oliveira, "senhora de grande beleza e muito querida pelos dotes de alma e de coração", cuja fraqueza ao ver do historiador Almeida Nogueira "fora o filho ilustre".

A família - pai, mãe e filho - passou a residir na Rua do Carmo, nas proximidades do Convento de Anchieta. Crispiniano, rebento de uma família pobre, enfrentando as vicissitudes de uma juventude sem amparo financeiro consegue terminar o curso de preparatórios e se matricula no curso acadêmico do largo de São Francisco.

Para seu sustento, exerce as funções de porteiro do Conselho Geral da Província. Segundo informes que não são trazidos pelo historiador Arthur Mendes, "Crispiniano vinha de obscura camada social e nem desassombradamente usava o nome que trazia. Daí a origem duma desconfiança, o germen duma cólera morando, ambas, em seu espírito, ambas tentando empecer-lhe os movimentos. Contra isso reagia habilmente, procurando envaidecer-se do que havia sido e com quem havia chegádo a ser".

Como se sabe, em 1827 deu-se a criação dos cursos jurídicos no Brasil, acontecimento esse que iria influir extraordinariamente no espírito daquele que, futuramente, teria assento no seu corpo docente.

A cidade de São Paulo, à época, não se expandira, como assinala Spencer Vampré "ficara equilibrada nas pontas dos despenhadeiros, receosa de escorregar pelas ladeiras lamacentas, toda sarapintada de lama".

Aos 21 anos de idade, matriculou-se Crispiniano na Academia; dentre seus colegas Joaquim Inácio Ramalho, Francisco Bernardino Ribeiro, Padre Ildefonso Xavier Ferreira, João Carlos da Silva Telles, José Ildefonso de Souza Ramos, Joaquim Octaviano Nébias, Francisco de Paula Negreiros, Josino do Nascimento Silva, Carlos Antonio Cordeiro e Antonio Augusto Queiroz.

Desses, três mais tarde tomariam assento dentre os membros da Congregação da Academia; e Crispiniano seria um deles.

No ano de 1830 , quando de sua matrícula, não foi realizada a tradicional comemoração com que estudantes e professores saudavam o aniversário do imperador D. Pedro I. É que nesse ano acontecimento de graves conseqüências 
abalou os habitantes da pacata cidade: o estúpido e traiçoeiro assassinato do jornalista Líbero Badaró.

Ao concluir o terceiro ano do curso jurídico, em razão das notas obtidas, entendeu a Congregação da Academia em conceder ao acadêmico Crispiniano um prêmio, constante de diploma assim redigido:

"A Congregação Geral dos Lentes da Academia de Sciencias Jurídicas da cidade de São Paulo, atendendo a brilhante maneira por que o Sr. João Crispiniano Soares, natural desta cidade, se dintinguiu entre os seus condiscípulos, nas aulas do terceiro ano, já pela aplicação e conhecimentos que com ele adquiriu, já pela honrosa conduta; e querendo dar-lhe testemunho do alto grau em que presa o seu conhecimento, lhe dá este título, para prova perpétua de que lhe foi conferido um dos prêmios do Mérito Literário, decretado pelo artigo $2^{\circ}$ do Capítulo 12 dos Estatutos da mesma Academia. São Paulo, 27 de março de 1833. (A (a) José Arouche de Toledo Rendon - Diretor).

\section{Prudêncio Geraldo Tavares Cabral - lente da $1^{a}$ Cadeira do 5o ano;}

Carlos Carneiro de Campos - Secretário Geral da Academia.

Contava então Crispiniano nessa ocasiāo 24 anos de idade; em 1834 finalizava seu curso na Academia, recebendo o grau de Bacharel, mas permanece ainda um ano a mais como aluno para conseguir o título de Doutor em Direito.

Todavia, apenas um ano depois, retorna à Academia e já como lente de Direito. É que ao terminar o curso de Doutorado resolveu Crispiniano prepararse para o concurso de lente-substituto. Acompanhou-o nessa sua decisão o seu inseparável companheiro dos bancos acadêmicos, o futuro Barão de Ramalho. Ambos aprovados, foram nomeados lentes-substitutos por Decreto de 23 de abril de 1836; era Diretor da Academia, Costa Carvalho. Tornava-se, assim, Crispiniano, Lente de Direito da Academia, onde iria lecionar por 36 anos, até a sua morte.

Quanto ao tipo físico do novo lente, deixemos que Almeida Nogueira o retrate como "alto, cheio de corpo, lábios finos, olhar ligeiramente estrábico, cabelos negros, bigodes raspados; expressão grave, quase severa. Colarinhos levantados, sobrecasaca preta, chapéu alto, gravata de volta de setim preto".

Os seus contemporâneos complementam que Crispiniano tinha um costume interessante: era o de aparecer por vezes às aulas vestido de calças brancas... os que lhe conheciam os hábitos sabiam de antemão que, nessas ocasiōes, ele estava de mau humor. Certamente, alguma chamada sobre o ponto dado em aula anterior poderia ocorrer e tratavam os calouros de se safar a tempo. 
Segundo os que com ele conviveram, o orgulho em demasia era o seu grande defeito, o que aliás não escondia: jamais permitia qualquer observação à Cátedra. Seus conhecimentos de história eram de tal ordem que Júlio Frank assim se expressou: "É uma cabela de Guizot".

Até o ano de 1854, quando se tornou catedrático de Direito Romano, Cadeira criada e incluída no curriculum das faculdades de Direito não lecionou ininterruptamente, uma vez que diversas vezes Crispiniano se afastou da Academia para ocupar altos cargos na administração pública.

As aulas ele as dava, de início, em tom de voz bastante moderada, mas entusiasmava-se gradativamente com o assunto e acabava por fazer gritaria que era ouvida até fora do recinto da Academia.

Certo dia chegot-lhe aos ouvidos de que o lente Furtado andava se queixando do seu sistema de lecionar, ou seja, aos berros. Crispiniano com o seu peculiar orgulho limitou-se a dizer: "eu ergo a voz, porque tenho confiança no que digo. Não receio errar; não temo que o mundo inteiro me ouça".

Quando descorria sobre o ponto, tinha como hábito, ao fazer as suas afirmações, o emprego do advérbio "indubitavelmente". Não raras vezes, em aula, dizia: "Indubitavelmente Papiniano errou..., ou Cujacio, Donello são dessa opiniāo, mas eu, todavia, acho que eles erraram e penso de maneira diferente".

Como compêndio, adotava o de Waldeck ("Institutiones Iuris civilis Heineccianae Emendatae atque Reformatae"). Mais tarde, substituiu-o pela obra de Warnkoenig. Segundo nos informa o Professor e Emérito romanista José Carlos Moreira Alves, em artigo citado, a substituição "foi elogiada por Antonio Joaquim Ribas, na memória histórica da Faculdade para o ano de 1856, o qual acentuou que "a substituição se justificava pelos progressos que tem feito o estudo do direito e das antiguidades romanas, graças aos esforços de Niebuhr, Hugo, Savigny e tantos outros espíritos investigadores e perspicazes".

Certa vez afirmou: "para entender Von Savigny é preciso ler Puchta, e neste País só eu tenho Puchta".

$\mathrm{Na}$ história da Academia, os bedéis estavam sempre ligados aos lentes titulares e os acompanhavam por toda a vida universitária. $\mathrm{O}$ bedel de Crispiniano chamava-se Firmino e era chegado a um bom vinho, que os alunos proporcionavam...

Pelos estatutos da Academia, o aluno que alcançasse quarenta faltas perderia o ano. Quando tal ocorria, a solução era apelar para o Firmino, que "acertava as contas", mediante algumas garrafas de vinho... 
Ao chegar ao fim do ano, antes de iniciar a sua preleção, Crispiniano tirava do bolso o lápis e punha-se a somar os pontos perdidos pelos seus alunos: "O Sr. Fulano de Tal perdeu o ano: quarenta faltas!"

- Peço perdão ao Senhor Conselheiro: o Senhor Fulano deu 35 e não quarenta faltas!, dizia Firmino.

- Dou a sua conta como certa, Senhor Firmino. O Senhor tem a fé pública!, retrucava Crispiniano.

Mas, o certo é que a estudantada respeitava-o. Segundo Ferreira Rezende em "Minhas Recordações", Crispiniano era "uma espécie de gigante em cuja boca via-se pintado o orgulho e o desprezo".

Certa ocasião, examinava o Mestre de Direito Romano: ponto sorteado "Capitis Diminutio". O aluno foi logo dizendo: "os romanos tinham três cabeças..." Ao que interrompeu Crispiniano:

- Mais felizes do que o senhor que não tem nenhuma!...

Quando da reforma dos cursos jurídicos, em 1851, foram criadas duas novas cadeiras: a de Direito Romano e a de Direito Administrativo. Era a oportunidade tanto para Crispiniano quanto a Ramalho de se tornarem catedráticos. As aludidas cadeiras foram objeto do Decreto $n^{\circ}$ 608, de 1851, referendado por José da Costa Carvalho, Visconde Monte Alegre.

Em seus três artigos autorizados, o primeiro autorizava o governo a modificar os estatutos dos cursos jurídicos; o segundo criava as duas cadeiras e, finalmente, o terceiro dizia respeito à imediata execução do novo estatuto.

Como foi dito, tanto Ramalho quanto Crispiniano envidaram todos os esforços para serem nomeados. Para tanto, peticionaram junto ao Imperador, expondo suas pretensões e solicitando ainda que o Diretor da Academia informasse ao Senhor Ministro da Justiça sobre os pedidos que acabavam de fazer.

O Diretor da Academia enviou, em conseqüência, ofício ao Ministro do Império, cujo teor é o seguinte:

Ilmo. e Exmo. Senhor:

Requerendo os Drs. João Crispiniano Soares e Joaquim Ignácio Ramalho, lentes substitutos do Curso Jurídico desta cidade, que informe o requerimento que levaram à augusta presença de S.M. o Imperador, pedindo o primeiro a cátedra de Direito Romano e o segundo a cadeira de Direito Admi- 
nistrativo, novamente criadas, tenho a honra de levar ao conhecimento do mesmo augusto senhor, que os suplicantes foram providos lentes sulstitutos desta Academia em 23 de abril de 1836 e empossados a 28 de maio do mésmo ano, sendo por isso os mais antigos nesse exercício, no qual têm desempenhado cabalmente os seus deveres, estando quase sempre em efetivo exercício, lecionando as cadeiras de alguns proprietários que se acham impedidos. $O$ primeiro suplicante regeu efetivamente a segunda cadeira do quinto ano, mas nos anos de 1837 a 1850, além de ter suprido diversas outras cadeiras nos outros anos. $O$ segundo suplicante regeu efetivamente a primeira cadeira do segundo ano de 1836 a 1837, a cadeira de Economia Política, a primeira do quinto ano de 1838 até julho de 1844 e, nos anos de 1849-50 e 1851, a cadeira de Direito Civil, a primeira do quarto ano. Além disto, tem regido interinamente a cadeira de Aritmética e Geometria. O mesmo suplicante, antes que fosse nomeado lente-substituto, foi provido na cadeira de Filosofia Racional e Moral no ano de 1834. Tanto um quanto o outro dos suplicantes têm-se préstado a todos os serviços desta Academia e sempre satisfatoriamente. Siendo tão reiteradas as provas de suas capacidades intelectuais e do zelo com que cumprem seus deveres tornam-se dignos da graça que pedem. Deus guarde... São Paulo, 24 de julho de 1851"'.

Entretanto, somente em 1854 é que Crispiniano e Ramalho foram providos nos cargos de professores catedráticos. A cadeira de Direito Administrativo, todavia, foi concedida a Silveira da Motta; a Ramalho coube as cadeiras de Direito Processual Penal e de Direito Civil, esta, aliás, até então regida por Silveira da Motta.

O curso de Direito Romano foi iniciado em 1854 pelo novo lente-catedrático, Crispiniano Soares. A assiduidade às aulas foi interrompida pelo exercício do governo das províncias de Minas Gerais e do Rio de Janeiro.

Ademais a famosa questão Mauá de quem era advogado obrigava-o a longas permanências na Corte. Durante sua ausência a cadeira foi regida por Leôncio de Carvalho.

Sentindo-se cansado e doente pede Crispiniano juntamente com o seu inseparável amigo Ramalho os benefícios da jubilação que lhe é concedida pelo Decreto de 22 de agosto de 1871 . Afastava-se, assim, da cátedra daquele que durante 35 anos a serviu com carinho e dedicação.

Escreveu o primeiro lente de Direito Romano algumas obras jurídicas, sendo que a principal delas não chegou a ser impressa; intitulava-se "Tratado sobre as fontes de direito positivo para servir de introdução a um curso de Direito Público". Foi escrito com a colaboração de Joaquim Ignácio Ramalho. É ainda de sua lavra o "Regulamento para a arrecadação da taxa dos legados e heranças e em por cento adicionais". 
Durante largo tempo de sua vida Crispiniano residiu à Rua do Carmo no número 88 , portanto, na mesma rua em que morou quando para aqui veio em companhia de sua mãe.

Faleceu o Conselheiro João Crispiniano Soares a 15 de agosto de 1876, em conseqüência de grave moléstia que há muito o perseguia.

O seu enterro realizou-se no dia 19 de agosto às 11 h00 da manhã que teve um grande acompanhamento. Pouco antes de expirar fez testamento, nomeando sua esposa herdeira universal de seus bens. O presidente da Província de São Paulo, doutor Sebastião José Pereira, o diretor da Faculdade de Direito, lentes e alunos da Academia, políticos, chefes dos liberais e altas autoridades estiveram presentes nas solenidades fúnebres, acompanhando o seu corpo - vestido com a beca de lente da Academia - até o Cemitério da Consolação, onde foi sepultado.

Honras militares foram prestadas ao ilustre morto por uma guarda de capitắo, que se achava postada em frente à sua residência, na Rua do Carmo.

Desaparecia, assim, do mundo dos vivos, a majestosa e imponente figura do enérgico lente de Direito Romano.

O jornal "A Província de Säo Paulo" relatando o triste acontecimento, no número de edição do dia 17 de agosto de 1876, escreveu: "Deu-se nesta capital, ante-ontem, 15 de agosto de 1876, a perda de um cidadão distinto e mui considerado naquele dia às 9 horas da manhã, em conseqüência de grave enfermidade de que fora atacada havia dias. Caracter íntegro e severo, jurisconsulto e advogado de primeira plana, a todos esses dotes são realmente pela circunstância de ser filho de seu próprio valor, sabendo erguer-se do mais obscuro nivel às mais brilhantes posições sociaes, e trilhando sempre a estrada larga que honra e da dignidade. É sem dúvida nesse ponto de vista que de melhor direito the cabe a imortalidade da consideração social e o elevado respeito que lhe consagra a admiração dos contemporaneos".

Realmente, Crispiniano soube honrar a sua terra natal. Sua existência foi dedicada por inteiro ao cultivo dos postulados do Direito. Foi um brilhante advogado, erudito jurisconsulto, respeitável político. Entretanto, acima disso tudo, e muito acima, Crispiniano foi um mestre de Direito.

ALMEIDA, Aluísio de - "A Revoluçāo Liberal de 1842".

BLAKE, Sacramento - "Dicionário Bibliográfico Brasilciro".

EGAS, Eugênio - "Galleria dos Presidentes de São Paulo". 
MARQUES, J.M. de Azevedo - "Apontamentos Históricos”, 2 vol.

MARQUES, Manoel Eufrágio de Azevedo - "Apontamentos Históricos, Geográficos, Biográficos, Estatísticos e Noticiosos da Província de São Paulo".

MARTINS, Antonio Egídio - "São Paulo Antigo".

MENDES, Artur - "Figuras Antigas", 1ำ vol.

MOREIRA ALVES, José Carlos - "Panorama da literatura romanística no Brasil", in "Index", junho/ 1976.

NABUCO, Joaquim - "Nabuco de Araújo".

NOGUEIRA, José Luiz de Almeida - "Tradições e Reminiscências:", São Paulo, 9 vols.

PRETO, Ouro - "Marinha D'outrora".

REZENDE, Francisco de Paulo Ferreira de - "Minhas Recordações".

SANT 'ANNA, Nuno - "São Paulo Histórico", vol. II.

TAUNAY, Afonso de - "São Paulo no século XVI", 1º vol.

USP, "Revista da Faculdade de Direito", vol. XXIV, 1928 e vol. XXXIV, 1938.

VAMPRÉ, Spencer - "Memórias para a história da Academia de São Paulo", Saraiva, São Paulo, 1924, 2 vols.

Documentos: "Relatórios apresentados à Assembléia Legislativa pelos Presidentes da Província de São Paulo", 1865.

"A Província de São Paulo", de 17 de agosto de 1876.

Jornal "O Correio Paulistano", de 17 de agosto de 1876. 